\title{
STUDI KEANEKARAGAMAN MAKROBENTOS DI WILAYAH KONSERVASI KURA-KURA UNIVERSITAS BENGKULU SEBAGAI SUMBER BELAJAR IPA
}

\section{(Diversity of Macrobentos in the Regional Conservation of Bengkulu University as a Resource Science Learning)}

\author{
Winda Zulistia $^{1 \star}$, Bhakti Karyadi ${ }^{2}$, Agus Susanta ${ }^{2}$ \\ ${ }^{1}$ Mahasiswa Pascasarjana S2 Pendidikan IPA Universitas Bengkulu \\ ${ }^{2}$ Dosen Pascasarjana S2 Pendidikan IPA Universitas Bengkulu \\ *windazulistia@gamail.com
}

\begin{abstract}
This study aims to determine the diversity of macrobentos that exist in the turtle conservation pond University of Bengkulu which serve as a source of learning science class VII MTsN 2 Bengkulu City. This research was conducted in February 2017 until May 2017. The sampling of macrobentos using a quadrant transect measuring $1 \times 1$ meter made of 6 quadrants. Based on the results of research conducted obtained 1,086 individuals belonging to macrobentos belonging to 3 genus namely, Bellamnya, Faunus, and Pomaceae. The data obtained were calculated based on macrobentos community structure consisting of population density (KP), relative abundance $(\mathrm{KR})$, presence frequency $(F K)$, Diversity Index $\left(H^{\prime}\right)$ and dominance index $(\mathrm{C})$. The macrobentos diversity index found in turtle conservation ponds is below 1.5, with the result it can be said that in both turtle conservation ponds it has low macrobentos diversity. Development of learning refers to the modified Dick \& Carey model. The lessons developed include Syllabus, RPP, LKPD, and performance appraisal instruments that are viewed from the students' process skills. The result of the validation of learning development shows that the teaching materials developed are very feasible in the test try to learners. The results showed that the average of students' process skills from the aspect of the highest performance performance was in good criteria. This is indicated by the percentage that reaches $67 \%$. While the criteria include very good reached $33 \%$. While for the result of measurement of process skill of student which counted by classical which counted on each indicator included into good category and very good.
\end{abstract}

Keywords: Makrobentos, Diversity, Student Process Skills

\begin{abstract}
ABSTRAK
Penelitian ini bertujuan untuk mengetahui keanekaragaman makrobentos yang ada pada kolam konservasi kura-kura Universitas Bengkulu yang dijadikan sebagai sumber belajar IPA kelas VII MTsN 2 Kota Bengkulu. Penelitian ini dilaksanakan pada bulan Februari 2017 sampai bulan Mei 2017. Pengambilan sampel makrobentos dengan menggunakan transek kuadran yang berukuran $1 \times 1$ meter yang dibuat sebanyak 6 kuadran. Berdasarkan hasil penelitian yang dilakukan diperoleh 1,086 individu makrobentos yang tergolong kedalam 3 genus yaitu, Bellamnya, Faunus, dan Pomaceae. Data yang diperoleh dihitung berdasarkan struktur komunitas makrobentos yang terdiri dari kepadatan populasi $(\mathrm{KP})$, kelimpahan relatif $(\mathrm{KR})$, frekuensi kehadiran $(\mathrm{FK})$, Indeks keanekaragaman ( $\left.\mathrm{H}^{\prime}\right)$ dan indeks dominansi (C). Hasil indeks keanekaragaman makrobentos yang terdapat pada kolam konservasi kura-kura berada di bawah 1,5, dengan perolehan tersebut dapat dikatakan bahwa pada kedua kolam konservasi kura-kura memiliki keanekaragaman makrobentos yang tergolong rendah. Pengembangan pembelajaran merujuk pada model Dick \& Carey yang dimodifikasi. Pembelajaran yang dikembangkan meliputi Silabus, RPP, LKPD, dan instrumen penilaian kinerja yang dilihat dari keterampilan proses siswa. Hasil validasi pengembangan pembelajaran menunjukkan bahwa bahan ajar yang dikembangkan sangat layak di uji cobakan kepada peserta didik. Hasil penelitian menunjukkan bahwa ratarata keterampilan proses siswa dari aspek kinerja kinerja yang paling tinggi berada pada
\end{abstract}


kriteria baik. Hal ini ditunjukan dengan presentase yang mencapai $67 \%$. Sedangkan yang termasuk kriteria sangat baik mencapai 33\%. Sedangkan untuk hasil pengukuran keterampilan proses siswa yang dihitung secara klasikal yang dihitung pada tiap indikator termasuk kedalam kategori baik dan sangat baik.

Kata kunci : Makrobentos, Keanekaragaman, Keterampilan Proses Siswa

\section{PENDAHULUAN}

Provinsi Bengkulu merupakan salahsatu provinsi yang memiliki sumber daya alam yang melimpah, baik sumber daya alam yang ada di laut maupun sumber daya alam yang ada di daratan. Dengan melimpahnya sumber daya alam yang ada, provinsi Bengkulu juga memiliki keanekaragaman ekosistem yang sangat tinggi, baik keanekaragaman ekosistem darat maupun keanekaragaman ekosistem perairan.

Konservasi merupakan upaya yang dilakukan suatu pengelola untuk menjaga dan melindungi sumber daya alam agar tidak mengalami kepunahan, menurut undang-undang No.5 tahun 1990 konservasi adalah pengelolaan sumber daya alam hayati serta keseimbangan ekosistemnya sehingga dapat lebih mendukung upaya kesejahteraan masyarakat dan mutu kehidupan manusia. Dalam ekologi, konservasi merupakan alokasi sumber daya alam untuk sekarang dan masa yang akan datang. Kegiatan konservasi meliputi konservasi in situ (habitat aslinya) dan konservasi ex situ (bukan habitat aslinya). Salah-satu contoh kegiatan konservasi secara in situ yaitu pada kawasan suaka alam dan kawasan pelestarian alam, sedangkan salah satu contoh konservasi secara ex situ yaitu kebun raya, kebun binatang dan tahura (Wiryono, 2012). Universitas Bengkulu merupakan salah satu lembaga yang sangat mendukung upaya konservasi, dengan menjadikan lingkungan kampusnya menjadi kawasan konservasi ex-situ. Dukungan tersebut terlihat pada upaya pelestarian kura-kura dengan menjadikan lingkungan Universitas Bengkulu menjadi wilayah konservasi bagi kura-kura. Salah satu komponen pendukung keberhasilan konservasi kurakura yaitu tersedianya pakan yang cukup serta habitat yang sesuai. Jenis pakan yang dibutuhkan kura-kura yaitu daun talas dan ikan. Untuk melihat habitat yang sesuai terhadap kura-kura, perlu adanya bioindikator terhadap perairan tersebut yaitu makrobentos. Makrobentos adalah hewan invertebrata yang dapat dilihat dengan mata telanjang yang hidup didasar dan sekitar bebatuan di dasar perairan.

Makrobentos dapat digunakan sebagai bioindikator suatu perairan, karena habitat hidupnya relatif tetap. Perubahan suhu dan $\mathrm{pH}$ air sangat mempengaruhi keanekaragaman makrobentos. Keanekaragaman makrobentos sangat bergantung pada toleransi sensitifitasnya terhadap perubahan lingkungan. Kisaran toleransi makrobentos terhadap lingkungan berbeda-beda. Komponen lingkungan baik hidup (biotik) maupun yang mati (abiotik) mempengaruhi keanekaragaman makrobentos, perairan yang berkualitas baik biasanya memiliki keanekaragaman jenis yang tinggi dan sebaliknya pada perairan yang buruk atau tercemar. Sejauh ini belum diketahui kepadatan makrobentos dan kualitas perairan kolam unib dan kolam taman pintar sebagai upaya dalam mendukung kegiatan konservasi kura-kura yang dilakukan di lingkungan universitas bengkulu.

Menurut Utami (2014) dalam Ningsi (2016) konservasi ex-situ yang dilakukan di area kampus UNIB dapat bermanfaat sebagai sumber belajar, dimana sala-satu sumber belajar yang dapat digunakan dalam pembelajaran IPA adalah dengan memanfaatkan lingkungan sebagai sumber belajar, pembelajaran yang terjadi akan bersifat kongkrit sehingga siswa tidak mengira-ngira objek pembelajaran berdasarkan imajinasinya, siswa dapat mengaitkan antara konsep yang dipelajari dengan kondisi nyata yang ada di lingkungan sehingga akan menguatkan konsep yang menjadikan pembelajaran 
menjadi bermakna dan menarik atau tidak membosankan.

Dalam meningkatkan kualitas pembelajaran, guru diharapkan dapat menggunakan berbagai cara agar pembelajaran dapat bermakna. Salah satu cara yang dapat dilakukan adalah dengan merancang pembelajaran yang dapat meningkatkan keterampilan proses sains siswa pada proses pembelajaran dan pemilihan sumber belajar yang sesuai dengan karakteristik materi pembelajaran. Salah satu cara yang dapat dilakukan adalah dengan mengembangkan pembelajaran berupa Lembar Kerja Peserta Didik (LKPD). Dengan pengembangan pembelajaran IPA di Sekolah MTsN 2 kota Bengkulu kelas VII, diharapkan dapat meningkatkan motivasi peserta didik dalam belajar dan meningkatkan keterampilan proses sains dalam mengobservasi, mengukur, interpretasi data, mangkomunikasikan dan menginferensi.

\section{METODE PENELITIAN}

Penelitian ini dilaksanakan pada bulan februari 2017 sampai bulan April 2017 di kawasan konservasi kura-kura Universitas Bengkulu, penelitian pengembangan pembelajaran dilakukan pada bulan april sampai bulan pada bulan februari 2017 sampai bulan April 2017 yang dilakukan di MTsN 2 Kota Bengkulu dan kawasan konservasi kura-kura. Pengambilan sampel makrobentos dilakukan dengan menggunakan metode transek kuadran berukuran $1 \times 1 \mathrm{~m}$ (Soegianto, 1994 ).

\section{PROSEDUR PENELITIAN}

Lokasi Penelitian dibagi menjadi empat (4) stasiun dengan luas tiap stasiun sama. Dimana keakuratan luas area lokasi penelitian menggunakan Global Position System (GPS) dan roll meter. Dimana pada masing-masing terdiri dari 6 plot pengamatan, keseluruhan plot pengambilan makrobentos berjumlah 24 plot dengan ukuran masing-masing plot $1 \times 1 \mathrm{~m}$.

\section{PENGUMPULAN DATA MAKROBENTOS}

Pengumpulan

makrobentos dilakukan dengan menggunakan jaring berbingkai, kemudian makrobentos dikelompokkan berdasarkan genus nya masing-masing.

\section{TEKNIK ANALISIS DATA}

Data makrobentos

$$
\text { dianalisis dengan menggunakan rumus : }
$$

1. Kepadatan populasi (K) Luas Area $\left(11,25 \mathrm{~m}^{2}\right)$

$$
\mathrm{K}=\underline{\text { Jumlah Individu Suatu jenis }}
$$

2. Frekuensi kehadiran (FK)

$$
\text { FK }=\frac{\text { Jumlah Kuadran Yang Di Tempati Suatu Jenis }}{\text { Jumlah Total Kuadran }} \times 100 \%
$$

3. Indeks keanekaragaman makrobentos

$$
\mathrm{H}^{\prime}=-\sum\left(\frac{n i}{N}\right) \log \left(\frac{n i}{N}\right)
$$

4. Indek Dominansi

$$
\mathrm{C}=\sum\left(\frac{n i}{N}\right)^{2}
$$

5. Kelimpahan relatif

$$
\mathrm{R}=\frac{n i}{N} \times 100 \%
$$

Pendidikanı uengan cara uesкrıpı kualitatif dengan menggunakan skor yang diperoleh. Jenis data dari serangkaian uji coba berupa data kuantitaif dan kualitatif. Kuantitatif diperoleh dari hasil tes uji coba skala kecil untuk menilai efektifitas dan seaangkan uala кuaııаı merupakan penilaian, tanggapan, saran-saran yang diperoleh dari hasil reviu ahli yaitu dosen pembimbing dan guru mata pelajaran IPA MTsN 2 Kota Bengkulu. 


\section{HASIL DAN PEMBAHASAN}

Berdasarkan hasil penelitian yang dilakukan, makrobentos yang berhasil ditemukan pada kedua kolam konservasi kura-kura dapat dilihat pada tabel dibawah ini.

\begin{tabular}{|l|l|l|l|l|}
\hline No & Kelas & Ordo & Family & Genus \\
\hline 1 & \multirow{3}{*}{ Gastropoda } & Pulmonata & Liymnacidae & Bellamnya \\
\cline { 4 - 5 } & & \multirow{2}{*}{ Mesogastropoda } & Potamididae & Faunus \\
\cline { 4 - 5 } & & Ampullariidae & Pomaceae \\
\hline
\end{tabular}

Pengukuran struktur komunitas makrobentos berdasarkan hasil penelitian terdiri dari kepadatan populasi (KP), kelimpahan relatif $(\mathrm{KR})$ dan frekuensi kehadiran (FK).

Tabel 4.2. Kepadatan Populasi (K), Kelimpahan Relatif (KR), Frekuensi Kehadiran (FK)

\begin{tabular}{|c|c|c|c|c|c|c|c|}
\hline \multirow{3}{*}{ No } & \multirow{3}{*}{$\begin{array}{c}\text { Janis } \\
\text { Makrobentos }\end{array}$} & \multicolumn{6}{|c|}{ Ekosistem Kolam Konservasi } \\
\hline & & \multicolumn{3}{|c|}{ Kolam Taman Pintar } & \multicolumn{3}{|c|}{ Kolam Pipi Putih } \\
\hline & & $\begin{array}{c}\mathrm{KP} \\
\text { Ind } / \mathrm{m}^{2} \text { ) }\end{array}$ & $\mathrm{KR}(\%)$ & $\mathrm{FK}(\%)$ & $\begin{array}{c}\mathrm{KP} \\
\text { Ind } / \mathrm{m}^{2} \text { ) }\end{array}$ & $\mathrm{KR}(\%)$ & $\mathrm{FK}(\%)$ \\
\hline 1 & Bellamnya & 0,238 & 100 & 77,842 & 0,018 & 61,111 & 71,526 \\
\hline 2 & Faunus & 0,062 & 79,166 & 20,276 & - & - & - \\
\hline 3 & Pomaceae & 0,006 & 22,221 & 2,889 & 0,006 & 30,444 & 23,776 \\
\hline
\end{tabular}

Berdasarkan data jumlah makrobentos yang diperoleh dari hasil penelitian kolam taman pintar dan kolam pipi putih, maka didapatkan nilai kepadatan populasi (KP), kelimpahan relatif $(K R)$, dan frekuensi kehadiran (FK) seperti tertera pada tabel 4.2 yaitu pada kolam taman pintar nilai kepadatan tertinggi adalah Bellamnya dengan jumlah kepadatan populasi $0,238 \mathrm{ind} / \mathrm{m}^{2}$, kelimpahan relatif (KR) $100 \%$ dan frekuensi kehadiran (FK) 77,842\%. Sedangkan pada kolam pipi putih kepadatan tertinggi adalah Bellamnya dengan jumlah kepadatan populasi (KP) $0,018 \mathrm{ind} / \mathrm{m}^{2}$, kelimpahan relatif $(\mathrm{KR})$ $61,111 \%$, dan frekuensi kehadiran (FK) $71,526 \%$.

Tabel 4.3. Indeks keanekaragaman ( $\left.\mathrm{H}^{\prime}\right)$ dan Indeks dominansi (C)

\begin{tabular}{|l|l|c|c|}
\hline No & Indeks & Kolam taman pintar & Kolam pipi putih \\
\hline 1 & Keanekaragaman $\mathrm{H}^{\prime}$ & 0,255 & 0,244 \\
\hline 2 & Dominansi C & 0,654 & 0,585 \\
\hline
\end{tabular}

Berdasarkan dari tabel diatas dapat dilihat bahwa nilai indeks keanekaragaman $\left(\mathrm{H}^{\prime}\right)$ dibawah 1,5. Nilai indeks keanekaragaman $\left(\mathrm{H}^{\prime}\right)$ pada kolam taman pintar yakni sebesar 0,255, sedangkan pada kolam pipi putih indeks keanekaragaman yakni sebesar 0,242, dilihat dari nilai indeks keanekaragaman kolam taman pintar dan kolam pipi dibawah 1,5 maka dapat dikatakan bahwa tingkat keanekaragaman makrobentos pada masing-masing kolam tergolong rendah. Keanekaragaman yang rendah menunjukan bahwa pada suatu komunitas tidak banyak terjadi interaksi antar jenis makhluk hidup. Menurut Brower et. al 
(1990) dalam Sinaga (2009) menyatakan bahwa suatu komunitas dikatakan mempunyai keanekaragaman spesies yang tinggi apabila terdapat banyak spesies dengan jumlah individu masingmasing spesies relatif merata. Dengan kata lain bahwa apabila suatu komunitas hanya terdiri dari sedikit spesies dengan jumlah individu yang tidak merata, maka komunitas tersebut mempunyai keanekaragaman yang rendah.

Tabel 4.4. Faktor abiotik kolam taman pintar dan kolam pipi putih

\begin{tabular}{|l|l|l|c|}
\hline No & Ekosistem & $\begin{array}{l}\text { Parameter yang } \\
\text { diukur }\end{array}$ & Hasil pengukuran \\
\hline \multirow{4}{*}{1.} & \multirow{4}{*}{ Kolam taman pintar } & Kedalaman & $2 \mathrm{~m}$ \\
\cline { 3 - 4 } & & Kekeruhan & 1,45 \\
\cline { 3 - 4 } & & Suhu & $29^{\circ} \mathrm{C}$ \\
\cline { 3 - 4 } & & Ph & 6,5 \\
\cline { 3 - 4 } & & COD & $0,32 \mathrm{mg} / \mathrm{L}$ \\
\cline { 3 - 4 } & & BOD & $0,1 \mathrm{mg} / \mathrm{L}$ \\
\hline \multirow{5}{*}{2.} & Kolam pendipa & Kedalaman & $1 \mathrm{~m}$ \\
\cline { 4 - 4 } & & Kekeruhan & 8,52 \\
\cline { 3 - 4 } & & Suhu & $27^{\circ} \mathrm{C}$ \\
\cline { 3 - 4 } & & pH & 6,5 \\
\cline { 3 - 4 } & & $\mathrm{COD}$ & $9,853 \mathrm{mg} / \mathrm{L}$ \\
\cline { 3 - 4 } & & $\mathrm{BOD}$ & $6,904 \mathrm{mg} / \mathrm{L}$ \\
\hline
\end{tabular}

Dari tabel diatas dapat dilihat bahwa pengukuran faktor abiotik kolam konservasi kura-kura meliputi : kedalaman, kekeruhan, suhu, pH, COD, dan BOD air kolam. Kedalaman kolam pada kolam taman pintar yaitu 2 meter sedangkan pada kolam pendipa 1 meter. Dengan kedalaman tersebut baik pada kolam taman pintar dan kolam pipi putih tidak mendukung pertumbuhan makrobentos dan juga kurangnya tumbuhan air disekitar kolam yang menyebabkan sumber bahan makanan makrobentos berkurang.

Bahan ajar yang dikembangkan dalam penelitian berupa Silabus, RPP, LKPD dan instrumen penilaian keterampilan kinerja dan keterampilan proses sains siswa. Analisis kurikulum dilakukan dengan cara mengidentifikasi kompetensi yang mengacu pada kurikulum 2013 mata pelajaran IPA kelas VII semester dua. Dari hasil analisis kurikulum dengan melakukan pemetaan kompetensi inti $(\mathrm{KI})$ dan kompetensi dasar (KD), maka hasil penelitian keanekaragaman makrobentos sesuai untuk materi interaksi makhluk hidup dengan lingkungannya pada sub bab interaksi dalam ekosistem kelas VII.E MTsN.

Setelah melakukan pemetaan $\mathrm{KI}$, $\mathrm{KD}$, dan analisis materi pembelajaran, tahap selanjutnya yaitu mengembangkan perangkat pembelajaran berupa silabus, Rencana Perangkat Pembelajaran (RPP), LKPD dan Instrumen penilaian meliputi keterampilan proses sains siswa dan penilaian kinerja siswa.

Sebelum melakukan pembelajaran outdoor dilokasi kolam konservasi kurakura Universitas Bengkulu terlebih dahulu semua perangkat pembelajaran divalidasi terlebih dahulu oleh validator untuk mengetahui kevalidan perangkat pembelajaran yang dikembangkan. Menurut Borg \& Gall (1989) dalam Sugiono (2011), untuk menentukan kelayakan produk dengan menguji keefektifan produk tersebut dengan menggunakan uji validasi untuk memperoleh syaran dan masukan penyempurnaan perangkat pembelajaran tersebut.

Pengukuran keterampilan proses siswa dalam penelitian ini yaitu meliputi keterampilan mengobservasi, keterampilan mengukur, keterampilan 
interpretasi data, keterampilan mengkomunikasikan dan keterampilan menginferensi (kesimpulan) yang dilihat dari aspek kinerja siswa dalam mengerjakan LKPD (Winarni, 2012).

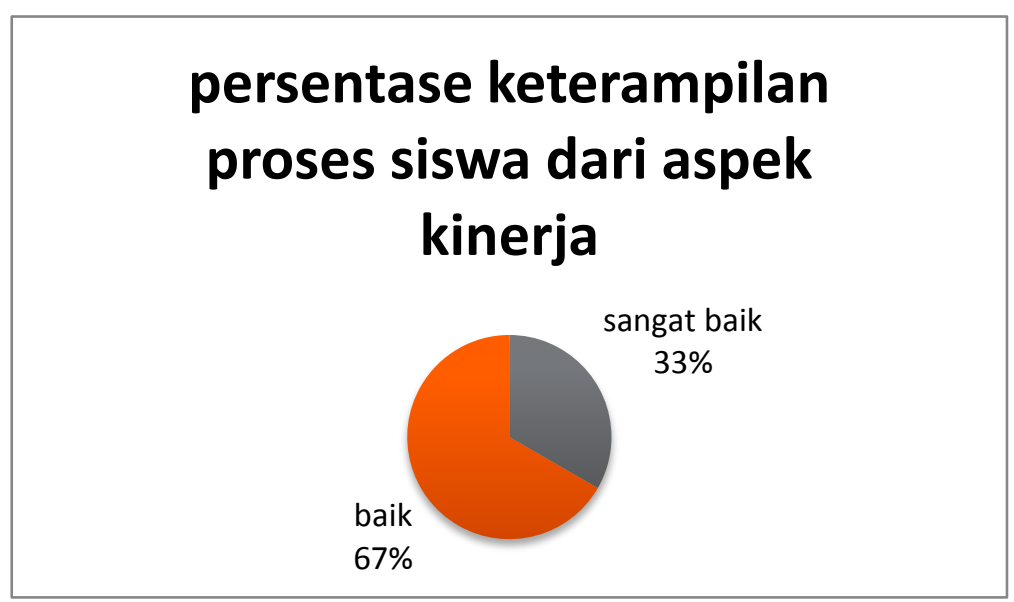

Grafik presentase keterampilan proses siswa dari aspek kinerja

Berdasarkan gambar diatas
menunjukan bahwa presentase keterampilan proses siswa dari aspek kinerja pada KD. 4.7 menunjukan bahwa rata-rata keterampilan proses siswa dari aspek kinerja yang paling tinggi berada pada kriteria baik. Hal ini ditunjukan dengan presentase yang mencapai $67 \%$. Sedangkan yang termasuk kriteria sangat baik mencapai 33\%. Perolehan presentase ketarampilan kemampuan proses siswa dari aspek kinerja merupakan hasil perolehan dari setiap aspek keterampilan proses siswa. Pengukuran keterampilan proses siswa

\section{DAFTAR PUSTAKA}

Andi, A. 2011. Panduan Kreatif Membuat Bahan Ajar Inovatif: Menciptakan Metode Pembelajaran Yang Menarik Dan Menyenangkan. Diva Press. Yogyakarta.

Dorajah, Y. 2005. Keanekaragaman Jenis Makrozoobentos Di Ekosistem Perairan Rawapening Kabupaten Semarang. Semarang. Skripsi.

Fachrul, F,M. 2007. Metode Sampling Bioekologi. Pt. Bumi Aksara. Jakarta.

Fadillah. N., 2016. Struktur Komunitas Makrozoobentos Sebagai juga aınıtung secara кıаsıkal untuk setiap aspek keterampilan proses. Data secara klasikal dari pengukuran keterampilan proses siswa dapat dilihat pada tabel dibawah ini.

\section{Ucapan Terimakasih}

Terimakasih buat pembimbingku Dr. Bhakti Karyadi, M.Pd dan Dr. Agus Susanta, M.Ed yang selalu membimbing , memotivasi dan memberikan arahan dalam menyelesaikan jurnal ini.

Indikator Perubahan Kualitas Perairan Disungai Belawan Kecamatan Pancur Kabupaten Serdang. Fakultas Pertanian, Universitas Sumatera Utara. Artikel.

Hasanudin. 2012. Bengkulu The Land Of Raflesia.

Karyadi., B. 2016. Pengembangan Model Pembelajaran di luar kelas (outdoor) berbasis lingkungan alam bagi siswa $S D, S M P, S M A$. Universitas Bengkulu.

Ningsi., P., E. 2016. Aklimatisasi Kurakura Pipi Putih (Siebenrockiella crassicollis) di area konservasi kura-kura Universitas Bengkulu 
dan pengembangan bahan ajar biologi SMA/MA. Bengkulu. Tesis.

Soegianto., A. 1994. Ekologi Kuantitatif. Surabaya. Indonesia.

Sugiono. 2011. Metode Penelitian Pendidikan. Alfabeta. Bandung.
Winarni., W., E. 2012. Inovasi Dalam Pembelajaran IPA. Unit Penerbitan FKIP UNIB

Wiryono. 2012. Pengantar IImu Lingkungan. Portelon Media. Bengkulu. 